\title{
GROWING BIGGER AND MORE ACCURATE WITH GSBPM (PART THREE)
}

\author{
Arbi Setiyawan ${ }^{1}$, Ni Lessari ${ }^{2}$, Hanik Devia ${ }^{3}$ \\ ${ }^{1}$ Government National Statistics Training Center, Indonesia \\ ${ }^{2}$ STIS National Statistical College, Indonesia \\ ${ }^{3}$ STIS 52 Computer Division, Indonesia \\ arbisetiawan@,gmail.com
}

Very different from other countries with only one language, Indonesia has more than three hundred local languages having more than seven hundred dialects. Currently all descriptions census and survey variables in questionnaire, data entry program, metadata, and interviewer guide book are available only in single national language. An interviewer may not be able to accurately translate variable descriptions from single national language to local languages and further to a particular dialect. This condition leads to misinterpretation and low accuracy in collected variables. We propose consolidation among local languages to produce official statistics variables at National Statistics College in the context of statistical education. Consolidation will produce multilingual official statistics equipment mentioned above. Every year there are several hundred new students at National Statistics College from almost every leading local language. These are untapped resources and are ready for this purpose. Data accuracy may be improved with multilingual descriptions variable. It will encourage a lot of information about a variable as much as local language but it will make data more accurate. There will be no biased variable because it has been explained in the local language. Generic Statistical Business Process Model (GSBPM) provides structured approach to arrive at more accurate data. A personal computer owned by every student offers far more ease and flexibility for review, validate, edit GSBPM sub-process during education. The academic campus has long standardized software to help for this purpose.

\section{DISCLAIMER}

These are authors' views and neither that of Government National Statistical Training Center nor STIS nor their officials. 